\title{
Design and Implementation of a Parabolic Cylinder Collector with Solar Tracking to obtain hot water
}

\author{
Wilson E. Sánchez ${ }^{1}$, Mario P. Jiménez ${ }^{1}$, Carlos A. Mantilla ${ }^{1}$, José M. Toro ${ }^{1}$, Miguel A. Villa ${ }^{2}$, Germánico Sinchiguano ${ }^{3}$ \\ Departamento de Eléctrica y Electrónica ${ }^{[1]}$, Departamento de Ciencias Exactas ${ }^{[2]}$, Unidad de Gestión de Tecnologías ${ }^{[3]}$, \\ Universidad de las Fuerzas Armadas ESPE, ID: 60104598, Sangolquí, Ecuador
}

\begin{abstract}
This investigation describes the design and implementation of a parabolic trough solar collector (PCC) with solar tracking to obtain hot water. The solar radiation available at the installation site is analyzed, followed by the design and construction of the mechanical system, making a series of calculations for the dimensioning of the reflective base, and a stress and deflection analysis of the structure is performed to verify the feasibility of the design in the ANSYS software. An analysis of the solar tracking system is performed, which is dimensioned from the PCC structure to determine the type of solar tracker to implement; The charging system, consisting of a solar panel and a battery, is dimensioned for the power supply of the tracking system; as a last point, for the heating system is determined the amount of water that is able to heat the system from the energy analysis at the installation site, the heating system is based on placing a Heat Pipe, in the focus of the parabola to receive the solar rays reflected by the collector and heat exchange to the water from a thermowell where the heat pipe condenser enters, finally tests are carried out in the PCC implemented obtaining a global efficiency of $16.37 \%$.
\end{abstract}

Keywords. Solar collector, PCC, solar tracking, solar panel, hot water

\section{Introduction}

The use of parabolic trough collectors can be found in different countries that promote the use of renewable energies, such as Mexico, Argentina or Paraguay as well as in Europe. one of the cases is the Mexican Eduardo Zarza's project, with his project theme "Direct generation of steam with parabolic trough collectors" he notes that "solar radiation is never high when the angle of rotation of the collectors are small" [1], he also concluded that "in no case of temperature differences have obtained greater than $41 \mathrm{~K} "$ [1]. In other works it is proposed that the parabolic trough collector becomes more efficient when installing the solar tracking device, because, first of all, the movement of the collector is continuous, thus describing a trajectory very close to that of the sun, which guarantees a better use of solar radiation [2], is related to the project outlined in this document, which aims to design and implement a parabolic trough collector with solar tracking to obtain water. On the other hand, currently in Ecuador, parabolic trough collectors have not been a subject of study and technological innovation.

\subsection{Solar radiation}

Radiation is electromagnetic waves which produce the transfer of energy, this occurs in all directions directly from the source [3].

\subsection{Parabolic trough solar collector}

The main characteristic of PCC's is that they have a linear focus and transform the direct solar radiation into thermal energy when a fluid is heated through a tube located in the focal axis of the same [4], its main components are:

- Parabolic cylindrical reflector: It is characterized by being a curved mirror, in the form of a parabola, which reflects and concentrates on the receiver tube the direct solar radiation that affects its area [5].

- Absorption tube or receiver: This is the core of the PCC, since the performance of the PCC itself depends on the thermodynamic capacity of the absorber [5].

- Solar tracking system: usually from east to west, i. e. the reflective base follows the sun during the day [6].

\section{PCCs DESIGN}

\subsection{Reflective base}


For the design of the reflective base, bright aluminium with a reflection coefficient of 0.853 was used to reflect the rays of the sun, whose dimensions are $1.75 \times 1.20$ meters. Calculations will be made for two focal lengths [7] of 25 and 35 centimeters. The length of the curve is determined by equation (1):

$$
S=\int_{a}^{b} \sqrt{1+f^{\prime}(x)} d x
$$

Already knowing the length of the curve $S=0.60 \mathrm{~m}$; we find the derivative $f^{\prime}(x)$ of the equation of the parabola, which is:

$$
f(x)=y=\frac{x^{2}}{4 \times F}
$$

Knowing the value of Xmax we can know the value of Ymax, replacing Xmax in the equation of the curve [8], obtaining the values that are represented in the table 1:

Table 1. Relationship Of Focal Lengths

\begin{tabular}{lll}
\hline Foco & $\boldsymbol{X} \boldsymbol{m a ́} \boldsymbol{x}$ & $\boldsymbol{Y m a ́ x}$ \\
\hline 0,25 & 0,49 & 0,24 \\
0,35 & 0,51 & 0,19
\end{tabular}

The aperture angle $\alpha$ and distance $\rho$ corresponding to the focal point is calculated with the parabola [9]. To calculate $\alpha$ proceed to the following calculation:

$$
\begin{gathered}
\operatorname{tg}\left(\frac{\alpha}{2}\right)=\frac{X \max }{F-Y \max }=\frac{0,51}{0,35-0,19}=3,1875 \\
\alpha=2 \times \operatorname{arctg}(3,1875)=145,164^{\circ} \\
\rho=\sqrt{X \operatorname{má} x^{2}+(F-Y \operatorname{má} x)^{2}} \\
\rho=\sqrt{0,51^{2}+(0,35-0,19)^{2}}=0,53 \mathrm{~cm}
\end{gathered}
$$

\subsection{Receiver tube}

Now we proceed to calculate the receiver tube diameter using the following equation:

$$
\begin{gathered}
\emptyset \min =\frac{2 \times \rho \times \operatorname{tg} 16^{\prime}}{\cos \left(\frac{\alpha}{2}\right)} \\
\emptyset \min =\frac{2 \times 0,53 \times \operatorname{tg} 16^{\prime}}{\cos \left(\frac{145,164}{2}\right)}=1,6 \mathrm{~cm}
\end{gathered}
$$

Using the value of focal length equal to $25 \mathrm{~cm}$, a minimum pipe diameter value of 22 centimetres is obtained [10]; therefore the focal length to be used in the project will be 35 centimetres.

\subsection{Water heating}

It is necessary to calculate the heat that will be received by the absorber tube coming from the reflective surface of the PCC, for this purpose a prototype of the system to be implemented to obtain the temperature values, as well as the necessary data for tank sizing [11]. With which the coefficient of losses in the tank is calculated, obtaining:

$$
U c=5,497 \mathrm{~W} / \mathrm{m}^{2} \mathrm{~K}
$$

The area of the receiver tube is obtained by the following calculation [12]:

$$
A_{r}=\pi \times 0,047 \times 1,80=0,265 m^{2}
$$

So the heat incident on the heat pipe is:

$$
Q_{\text {inc }}=486,19 \mathrm{~W}
$$

This data is used to calculate the minimum water mass that can be heated up to $60{ }^{\circ} \mathrm{C}$. As the heat pipe is located inside a thermowell for heat exchange in the tank, losses in the tank [13] are taken into account:

$$
\mathrm{Q}_{\text {perdidas }}=62,5 \mathrm{~W}
$$

This means that the useful heat delivered by the collector to the water stored in the tank must be

$$
\begin{gathered}
Q_{u t i l}=Q_{\text {inc }}-Q_{\text {perdidas }} \\
Q_{\text {util }}=486,19-62,5=423,69[W]
\end{gathered}
$$

Where the necessary heat

$$
\begin{gathered}
Q_{\text {nec }}=Q_{\text {inc }} \times 3600 \mathrm{~s}=423,69 \times 3600 \\
Q_{\text {nec }}=1525,28 \mathrm{~kJ} \\
Q_{\text {nec }}=m \times C p \times(T f-T i) \\
1525,28=m \times 4,18 \times(60-15,65) \\
m=8,22 \mathrm{~kg}
\end{gathered}
$$

Therefore, in one hour the PCC is capable of raising the water temperature from $15.65^{\circ} \mathrm{C}$ to $60^{\circ} \mathrm{C}$ from 8.22 liters of water, so the tank to be designed will be cylindrical and will have a capacity of 10 liters.

A water recirculation system is not necessary for the operation of the heating system because this water heating system was designed using the heat pipe heat exchange system, where the heat pipe condenser enters the storage tank through a thermocouple, which is where the heat exchange with the water takes place.

\section{PCC Implementation}

As soon as the design conditions for the calculated and simulated stress and deflection parameters in the ANSYS software are met. The system was built and implemented in the laboratory of Renewable Energies of the Universidad de las Fuerzas Armadas ESPE, Fig. 1, Fig. 2. 


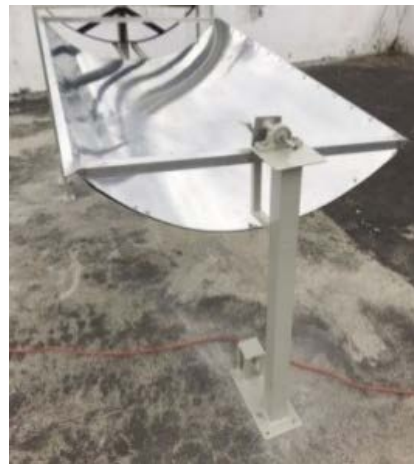

Figure 1. PCC constructed

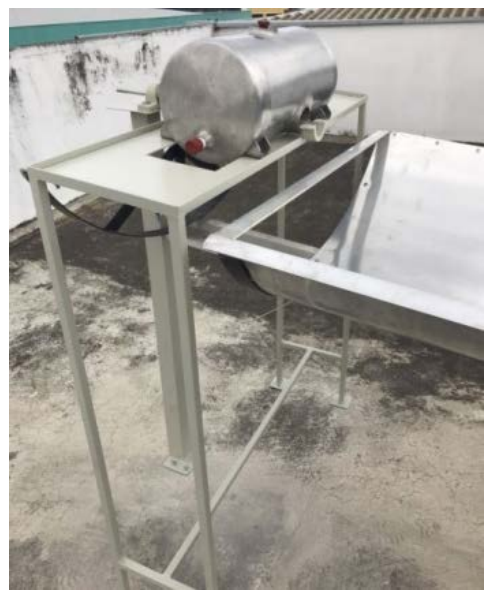

Figure 2. Built in heating system

The solar tracking is on one axis due to being near the equatorial line the solar declination in the solstices does not exceed $23.4^{\circ}$ according to the astronomy simulation software of the University of Nebraska-Lincoln with which the solar movement on Latacunga was analyzed, therefore a north-south tracking is not necessary.

\subsection{Power supply unit}

The necessary equipment was sized to power the tracking system based on its technical characteristics in order to have autonomy in the system.

\subsection{Battery}

The minimum capacity of the battery to be implemented in the project is calculated based on the technical characteristics of the solar tracker.

$$
\begin{gathered}
\text { Capacity }=\frac{E_{B}}{V}=\frac{135[\mathrm{Wh}]}{12[\mathrm{~V}]} \\
\text { Capacity }=11,25 \mathrm{Ah}
\end{gathered}
$$

Therefore, a $12 \mathrm{~V}$ battery with a capacity of at least 11.25 $\mathrm{Ah}$ is required. A solar charge controller of $5[\mathrm{~A}]$ is implemented in the system. In order to calculate the solar panel, the power required is $135 \mathrm{Wh}$, so the energy of the solar field is:

$$
E_{C S}=\frac{E_{d}}{\eta_{B}}
$$

$$
E_{C S}=\frac{108}{0,8}=135[\mathrm{Wh}]
$$

With this you get the power of the panel will be:

$$
\begin{gathered}
E_{p}=\frac{E_{C S}}{\text { Sun peak hours }(H S P)} \\
E_{p}=\frac{135}{5}=27[\mathrm{~W}]
\end{gathered}
$$

With this value, the solar panel must have a power greater than or equal to 27[W], so for this project is implemented a panel of 30[W].

\section{Results of the tests}

For the tests, initially the temperature of the water entering the tank was measured, the temperature at which the environment was found. During the tests, an eighth of a covered sky was obtained.

The measurements obtained are shown in Fig. 3, where the solar radiation on the installation site is represented throughout the test, and in Fig. 4, the water temperature in the tank versus time.

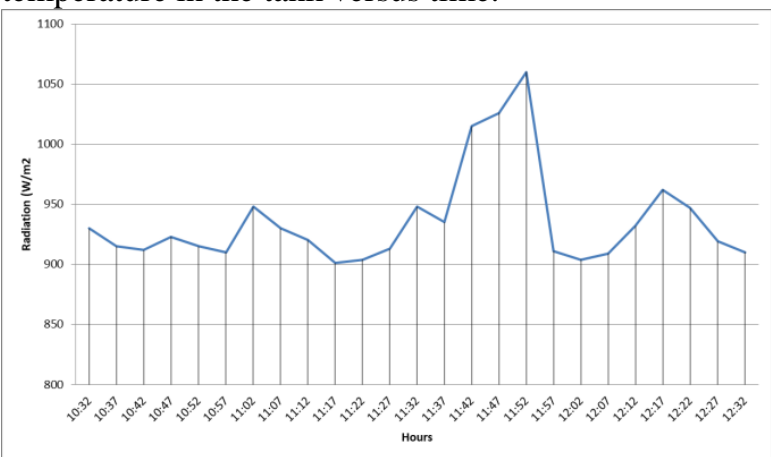

Figure 3. Solar radiation vs. time June 6

In Fig. 4, it is possible to observe solar radiation versus time, the incident energy of the sun during the two hours is $1873.25 \mathrm{Wh} / \mathrm{m} 2$.

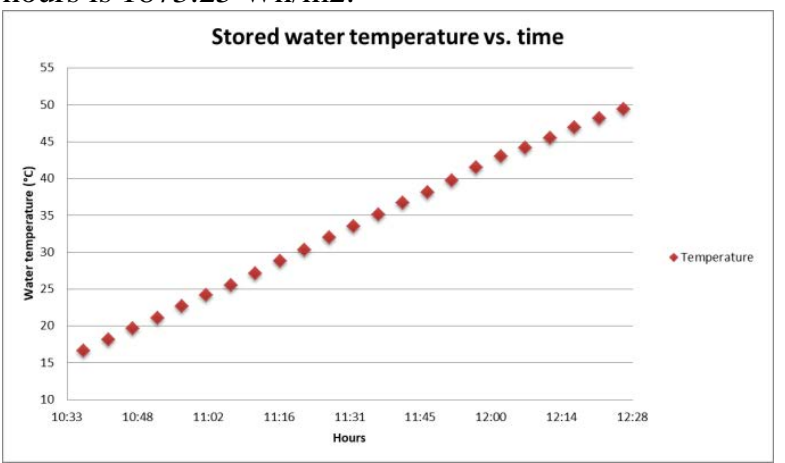

Figure 4. Storage water temperature vs. time June 6

Fig. 4, shows that the temperature of the water in the tank (represented on the $\mathrm{y}$-axis) increases from $15^{\circ} \mathrm{C}$ to $50.2^{\circ} \mathrm{C}$ in two hours (the time is represented on the $\mathrm{x}$-axis of the graph).

This means that $1471.35[\mathrm{KJ}]$ of useful energy was produced during two hours through the implementation of the Heat Pipe heating system in the reflector base of the PCC, which allowed an increase in the temperature of the 
water stored in the tank of $35.2^{\circ} \mathrm{C}$. With the data obtained in practice, useful energy is calculated [14] based on the data obtained in practice, obtaining:

$$
\begin{gathered}
Q_{u t i l}=m \times C p \times\left(T_{f}-T_{i}\right) \\
Q_{u t i l}=10 \times 4,18 \times(50,2-15) \\
Q_{u t i l}=1471,36[\mathrm{KJ}] \\
Q_{u t i l}=1471,36[\mathrm{KJ}] \times \frac{1}{3600 \mathrm{~s}}=408,71[\mathrm{Wh}]
\end{gathered}
$$

The solar irradiation in the two hours of operation of the system is $1873.25(\mathrm{Wh} / \mathrm{m} 2)$, so the energy captured by the collector will be of:

$$
Q_{\text {in }}=S c \times E_{\text {sol }} \times \cos \theta
$$

$S c$ being the useful capturing surface of the reflector base with solar tracking, and $\theta$ the angle of solar incidence at the place of installation of the collector.

$$
\begin{gathered}
Q_{\text {in }}=1,5418 \times 1873,25 \times 0,8643 \\
Q_{\text {in }}=2496,25[\mathrm{Wh}]
\end{gathered}
$$

With this we will have a global efficiency [15] of:

$$
\begin{gathered}
\eta=\frac{Q_{u t i l}}{Q_{\text {in }}} \\
\eta=\frac{408,71}{2527,23} \\
\eta=0,1637=16,37 \%
\end{gathered}
$$

Therefore the system has a global efficiency of $16.37 \%$.

\section{Conclusions}

A parabolic trough collector was designed, oriented to the north with an inclination of $6^{\circ}$ with respect to the horizontal one with east-west solar tracking controlled by a photovoltaic sensor; by means of the implementation of the Heat Pipe heating system in the focus of the reflective base of the PCC 1471,35 [KJ] of useful energy was produced during two hours, which allowed to have an increase of temperature of the water stored in the tank of $35,2^{\circ} \mathrm{C}$.

The overall performance of the system was $16.37 \%$ since the solar incident energy on the collector was 2527.23 Wh and the useful energy used by water to raise its temperature from $15^{\circ} \mathrm{C}$ to $50.2^{\circ} \mathrm{C}$ was 408.71 [Wh].

Glossy aluminium with a coefficient of reflection of 0.853 was used for the reflective base in order to reflect the sun's rays and, at the same time, low weight; the structure of the system was constructed of A36 steel and painted in the oven to withstand adverse climatic conditions, the storage tank is constructed of stainless steel.

The solar tracking system has autonomy for its operation through its power supply, which was designed by means of a solar panel and a battery, because it has a DC motor that moves an actuator by means of gears at a speed of $5.7 \mathrm{~mm} / \mathrm{s}$ and has a protection class IP54 for the actuator and IP65 for the control box.
By means of a four-channel digital thermometer, to which type $\mathrm{K}$ thermocouples are connected, the water temperature is measured at the tank inlet, in the water stored inside the tank and in the Heat Pipe condenser; solar radiation is measured by means of a pyranometer during system operation.

\section{References}

1. E. Zarza, "Generación Directa de Vapor con Colectores Solares Cilindro Parabólicos Proyecto DIrect Solar Steam (DISS)," Sevilla, 2003.

2. J. Fabara, Desarrollo experimental de un sistema de seguimiento solar para la obtención de la máxima radiación en concentradores cilíndrico parabólicos, Sangolquí: ESPE, 2016.

3. P. D. Tagle, A. Agraz y C. Rivera, «Study of applications of parabolic trough solar collector technology in Mexican industry,» Instituro Tecnológico y de Estudios Superiores, Monterrey, 2016.

4. A. Z. Fafez, A. M. Attia, H. S. Eltwab, A. O. ElJousy, A. A. Afifi, A. G. AbdEihamid, A. N. AbdElqader, S. Fateen, K. A. ElMetwally, A. Soliman y M. Ismail, «Design analysis of solar parabolic trough thermal collectors,» India, 2017.

5. C. Echeverria, «Diseño de un colector cilindro parabólico compuesto con aplicación para el calentamiento de agua,» Universidad de Pirhua, Piura, 2011.

6. J. Macedo Valencia y J. Ramirez Avila, «Design, construction and evaluation of Parabolic trough collector as demostrative prototype,» Quintana Roo: Departamento de Ingeniería, 2013.

7. C. Paredes, «Diseño de captador solar cilíndrico parabólico para aplicaciones rurales en Paraguay,» Asunción, 2012.

8. F. Mahjouri, «Vacuum Tube Liquid-Vapor (HeatPipe) Collectors,» Thermo Technologies, 2015.

9. Y. Garcia Ortiz, J. Yañez Mendiola y L. Valenzuela, «Cylindrical parabolic collectors material from low cost (stainless steel) applied to dried hybrid energy system,» Dyna, 2016.

10. J. A. Carta Gonzales y R. Calero Pérez, Centrales de energías renovables, Madrid: Pearson, 2013.

11. B. Nafiz Ahmed y E. Farzana Mollick, «Development and performance test of an evacuated tube solar water heater,» Department of Mechanical Engineering Khulna University of Engineering \& Technology, Khulna-9203, Bangladesh, 2016.

12. R. Cuestas y I. Rincón, «Diseño y construcción y evaluación operacional a pequeña escala de un potabilizador solar parabólico para agua,» Bucaramanga, 2011. 
13. F. Incropera, Fundamentos de transferencia de calor, Mexico D.F.: Prentice Hall Hispanoamericana, 1999.

14. R. Cherian y L. G. Lasithan, «Performance enhancement of solar water heater using compound parabolic reflector and numerical simulation of thermal lossees,» College of Engineering, India,
2016.

15. Y. Cengel, Transferencia de calor y masa, Ciudad de México: McGraw Hill, 2007. 